physical external trauma, but also mental external trauma. Furthermore, the students were especially drawn to human relationship matters concerning friends and their school, as well as situations of external trauma in terms of the perpetrator, victim and third person. Moreover, the students were able to identify places of risk going to and from school, although they were unwilling to share details pertaining to that particular data.

\title{
0295 THE DEVELOPMENT OF THE EDUCATIONAL THEME OF THE TRAUMA PREVENTION AT JAPANESE HIGH SCHOOL STUDENTS
}

YKojima*, IKenmochi, HKojima, SYamazaki, K Kuroda, M Yokoyama Correspondence: Tokai University, 148 Simokasuya, Isehara-city, Kanagawa-Pref, 243-0418, Japan

\subsection{6/ip.2010.029215.295}

In Japan, the cause of death between the age of 15 and 19 due to suicide and incidents were $60.2 \%$ in 2008 . Even though high school students tend to be overly concerned about their own physical well-being, especially in regards to external injuries, they tend to exhibit a low interest in personal prevention and little knowledge of Safety and Risk Management. Therefore, PARTY (Prevent Alcohol and Risk-related Trauma in Youth) Isehara, established Traffic and Sports External Trauma Prevention classes to be taught at the high school level in Japan. The classes are designed to prevent trauma that they, the students may inflict upon themselves or others as well as to help those in need of assistance. To enhance student interest in External Trauma Prevention, PARTY Isehara conducted a content analysis study asking students to define and explain external trauma in their own words. The purpose of the study was to determine the level of motivation of the high school participants for 2006-2009. The results indicated that the students were highly interested in not only 